Guest Editorial

\title{
Millennium Development Goals (MDGs): A Global Policy Paradox
}

Michel D. Landry PT, PhD, Department of Physical Therapy, Faculty of Medicine, University of Toronto (Canada); Department of Health Policy and Administration, School of Public Health, University of North Carolina at Chapel Hill (USA)

Sudha Raman PT, MSc, Department of Epidemiology, School of Public Health, University of North Carolina at Chapel Hill (USA)

Dr Michel D. Landry, Department of Physical Therapy, University of Toronto, 160-500

University Avenue, Toronto, Ontario, Canada, M5G 1V7, Tel: 416-946-8560, Fax: 416-946-8562,

Email: mike.landry@utoronto.ca

ealth status is connected with factors such as the environment, trade, economic growth and national security. Due to these close associations, health has emerged as a mediating factor inherent to a nation's prospect for human development. The concept of human development is the extent to which people living in a community, region or country are able to fulfill their human rights and achieve personal aspirations. The Human Development Index (HDI) is a composite score used by the United Nations Development Programme (UNDP) to rank countries in terms of their human development status. Most regions of the world have shown improvement in the HDI between 1975 and 2003. However, the HDI of many low-income or developing nations, particularly within Sub-Saharan Africa (SSA), has declined since the late 1980s, creating a widening gap between the so-called rich and poor countries (UNDP 2005; Birn 2005).

In recognition of the widening gap in real and potential human development, the United Nations initiated a global campaign called Millennium Development Goals (MDGs) (UN 2005). The MDGs were adopted in 2000 as a framework aimed at scaling up the development process (Dodd and Cassels 2006). There are eight internationally agreed upon MDGs, measured by a series of 48 indicators geared at reducing economic, social and health disparities in developing nations. 
Table 1. Millennium Develop Goals (MDGs) (UN 2005)

\section{Goal 1: Eradicate extreme poverty and hunger}

- Reduce by half the proportion of people living on less than a dollar a day

- Reduce by half the proportion of people who suffer from hunger

\section{Goal 2: Achieve universal primary education}

- Ensure that all boys and girls complete a full course of primary schooling

\section{Goal 3: Promote gender equity and empower women}

- Eliminate gender disparity in primary and secondary education preferably by 2005, and at all levels by 2015

\section{Goal 4: Reduce child mortality}

- Reduce by two thirds the mortality rate among children under five

\section{Goal 5: Improve maternal health}

- Reduce by three quarters the maternal mortality rates

\section{Goal 6: Combat HIV/AIDS, malaria and other diseases}

- Halt and begin to reverse the spread of HIV/AIDS

- Halt and begin to reverse the incidence of malarial and other major diseases

- Halt and begin to reverse the incidence of tuberculosis

\section{Goal 7: Ensure environmental sustainability}

- Integrate the principles of sustainable development into country policies and programs; reverse loss of environmental resources

- Reduce by half the proportion of people without sustainable access to safe drinking water

- Achieve significant improvement in lives of at least 100 million slum dwellers, by 2020

\section{Goal 8: Develop a global partnership for development}

- Develop further an open, rule-based, predictable, non-discriminatory trading and financial system

- Address the special needs of the least-developed countries, landlocked countries and small island developing states

- Deal comprehensively with developing countries' debt

- In co-operation with developing countries, develop and implement strategies for decent and productive work for youth

- In co-operation with pharmaceutical companies, provide access to affordable essential drugs in developing countries

- In co-operation with the private sector, make available the benefits of new technologies, especially information and communication technologies

Source: www.un.org/millenniumgoals/goals.html

The 15-year period dedicated to the MDGs (2000-2015) has now reached the midway point, and the overall success of the initiative has been mixed. The United Nations estimates that some of the targets have already been met, whereas others are expected to be met in the next few years (UNDP 2007). However, sadly, the majority of MDGs are unlikely to be reached by 2015 (Davey et al. 2006; Olusanya 2006; Jansen 2007; Potts and Fotso 2007). Although some regions such as Northern Africa and South-Eastern Asia are progressing relatively well, SSA continues to be a particular concern: half of the indicators have demonstrated either no progress or reversal in the gains made from the 1990s (UNDP 2007). In recognition of this, the United Nations SecretaryGeneral has convened a steering committee to get SSA on track before 2015. The goals set by this committee are threefold: first, to identify effective mechanisms for implementing commitments in the areas of health, education, agriculture, food security, infrastructure and statistical systems; second, to improve aid predictability; and third, to strengthen joint efforts at the country level in support of the MDGs. The difficulty lies in the empirical measurement of these and other macrolevel goals. In recently published editorials, it is consistently argued that progress of the MDGs is almost impossible to gauge due to the lack of valid and reliable population data (Anonymous 2007; Murray 2007; Lawn et al. 2007). In response, the United Nations Statistical Division acknowledged these deficiencies, but, as might be expected, they also signalled that progress is being made (Cheung 2007). It is important to highlight that developing countries are not alone in this data conundrum. 
Countries at all levels along the development continuum repeatedly deal with lack of data and tend to always signal the need for more and better data.

At the MDGs' midpoint, it can be argued that the process of identifying a series of specific and theoretically measurable goals has indeed served to reset the global development agenda among multiple stakeholders ranging from governments, policy makers and researchers to local communities. The MDGs have also served to create a common vision and discussion platform regarding the key aspects of the development process and have set the framework for comparisons among regions and countries. In her seminal book Policy Paradox: The Art of Political Decision Making, Stone argued that the intrinsic policy goals of a program or intervention can be quite different from the expected or extrinsic goals (Stone 1997). In other words, sometimes "losing" is in fact "winning." If the MDGs are not achieved by 2015 , and by most accounts they will not be, many stakeholders will view the outcome as yet another example of the international community's failure to meet its own targets. On the other hand, from an analytical policy perspective, the intrinsic and extrinsic goals of the program should be questioned prior to judgment. For instance, it would be instructive to examine whether the overall extrinsic goal of the MDGs was designed to be a realistic, measurable and time-limited event, or, from an intrinsic perspective, were the MDGs designed to set the direction of future human development? Perspective, values and interests surrounding this issue will certainly drive the individual and collective final opinion in this regard, but global programs such as the MDGs represent a complex policy paradox that is riddled with challenges in terms of structure, processes and outcomes.

In the end, MDGs may achieve a policy goal by highlighting the embarrassing discrepancies in human development that exist between countries and regions, along with the scale of the international financing and action required to address these discrepancies. The MDGs may not achievable by 2015; however, from a global policy perspective, they will surely set in place a framework through which to more fully appreciate the multi-dimensional health, economic and social factors that contribute to human development. If in time this understanding leads to a long-term commitment to action at the community, country and international levels, then, irrespective of the success of the stated extrinsic goals, the achievement of the intrinsic goals of the MDGs - the promise of more equal global human development - may be the ultimate legacy of the MDGs.

\section{References}

Anonymous. 2007. “Millennium Development Holes.” Nature 446(7134): 347.

Birn A-E. 2005. "Gates's Grandest Challenge: Transcending Technology As Public Health Ideology." Lancet 366(9484): 514-9.

Cheung, P. 2007. "Letter to the editor of Nature." Retrieved October 5, 2007. <http://mdgs.un.org/unsd/ $\mathrm{mdg} />$

Davey, G., D. Fekade and E. Parry. 2006. "Must Aid Hinder Attempts to Reach the Millennium Development Goals?” Lancet 367(9511): 629-31.

Dodd, R. and A. Cassels. 2006. "Health, Development and the Millennium Development Goals" Annals of Tropical Medicine \& Parasitology 100(5): 379-87.

Jansen, A. 2007. “Shed Some Light on Darkness: Will Tanzania Reach the Millennium Development Goals?” Acta Paediatrica 96(6): 781-6.

Lawn, J.E., A. Costello, C. Mwansambo and D. Osrin. 2007. "Countdown to 2015: Will the Millennium Development Goal for Child Survival Be Met?” Archives of Diseases in Childhood 92(6): 551-6.

Murray, C.J. 2007. "Towards Good Practice for Health Statistics: Lessons from the Millennium Development Goal Health Indicators.” Lancet 369(9564): 862-73.

Olusanya, B. 2006. "Disabilities, Physicians and the Millennium Development Goals." Disability \& Rehabilitation 28(4): 244.

Potts, M. and J-C. Fotso. 2007. "Population Growth and the Millennium Development Goals." Lancet 369(9559): 354-5.

Stone, D. 1997. Policy Paradox: The Art of Political Decision Making. New York, NY: WW Norton \& Company. 
United Nations. 2005. Millennium Development Goals. Retrieved October 17, 2007. <www.un.org/millenniumgoals/goals.html>

United Nations Development Programme. Human Development Report 2005. Retrieved September 12, 2007. <http://hdr.undp.org/>

United Nations Development Programme. Millennium Development Goals: 2007 Progress Chart. Retrieved October 3, 2007. <http://hdr.undp.org/hd/> 